Tropical Journal of Pharmaceutical Research April 2011; 10 (2): 117-123

(C) Pharmacotherapy Group,

Faculty of Pharmacy, University of Benin

Benin City, 300001 Nigeria.

All rights reserved.

Research Article

Available online at http://www.tjpr.org

\title{
Perceptions of Dispensers Regarding Dispensing Practices in Pakistan: A Qualitative Study
}

\author{
Azhar Hussain $^{1 *}$ and Mohamed IM Ibrahim ${ }^{2}$ \\ ${ }^{1}$ School of Pharmaceutical Sciences, University Sains Malaysia, 11800 Penang, Malaysia, ${ }^{2}$ Department of Social and \\ Administrative Pharmacy, College of Pharmacy, PO Box 6800, Al Qassim University, 51452 Buraidah, Al Qassim, \\ Saudi Arabia.
}

\begin{abstract}
Purpose: To explore the perceptions' of dispensers regarding dispensing practices and the salient factors affecting dispensing practices in three major cities of Pakistan - Islamabad, Peshawar and Lahore.

Methods: A qualitative study with snowball sampling technique was used to identify fifteen dispensers working in community pharmacies in Islamabad, Peshawar and Lahore. Semi-structured interviews were conducted with the dispensers until the point of saturation was obtained. The interviews which focused on three major components, namely dispensing practices, regulation and influencing factors, and suggestions for improvements were audio-taped, transcribed verbatim and analyzed.

Results: Thematic content analysis of the interview components yielded further seven major themes which were services provided at community pharmacies, quality of service provided by community pharmacies, expectation from community pharmacies, who was responsible for dispensing, obstacles to appropriate dispensing practices, laws and factors governing pharmacy practice in Pakistan, and strategies to improve current dispensing practices.

Conclusion: All respondents in the different cities agreed that there was a shortage of pharmacists leading to their roles being taken over by the non-professionally qualified personnel working in community pharmacies. They also agreed that implementation of laws governing pharmacy practice in Pakistan is weak. These two main factors were considered to be responsible for the low quality services provided at community pharmacies.
\end{abstract}

Keywords: Dispensers, Dispensing Practices, Pakistan, Qualitative methodology 


\section{INTRODUCTION}

Community pharmacies are the main supplier of medicines in developing countries. Pharmacy personnel are approached for medicines and advice on health problems [1]. Good dispensing practices require that the person responsible must ensure safe and effective dispensing of drugs for the patient. It is generally thought that a dispenser is a person with sufficient knowledge and appropriate skills to prepare and dispense medicines. The scenario in developing countries is different. Any person trained or untrained, who gives out medicines is a dispenser $[1,2]$.

Poor dispensing practices are evident by errors occurring in the transcription stage, incomplete dispensing, lack of proper counselling on drugs sold, drugs not being labelled and different drugs being mixed in the same package [2]. Dispensers hardly ever ask questions about the illness, and historical information obtained is inadequate to determine the nature or severity of disease or appropriateness of therapy [3-7]. Inappropriate dispensing and lack of proper counselling can lead to waste of resources and have a negative impact on the health of individuals as was well as on the health care system [8].

Several studies have been undertaken to identify the motivations, reasons and other factors responsible for current dispensing practices in different countries [8-10]. A study from Laos explored knowledge and perceptions among drug sellers and consumers regarding quality of medicines. It highlighted lack of knowledge among drug sellers and low awareness among consumers. Training of dispensers and provision of drug information for the public was recommended [11].

Dispensing practices in community pharmacies have been reported to be unsatisfactory in Pakistan, and previous studies conducted have highlighted the need for qualitative investigations to explore the underlying issues $[4,12]$. Therefore, the present study was designed to explore reasons and factors behind the prevailing low standards of dispensing practices in the country.

\section{METHODS}

\section{Study design}

A qualitative study was designed to explore the perceptions' of dispensers regarding dispensing practices and the salient issues and factors affecting dispensing practices in three major cities of Pakistan, namely, Islamabad (national capital), Peshawar (capital of Khyber Pakhtoonkhwa Province) and Lahore (capital of Punjab Province). The study protocol was approved by a panel of experts at the Research and Development Wing of Drug Control Organization, Ministry of Health, Government of Pakistan. Semi-structured interviews were conducted using in-depth interview guides to collect data.

\section{Sample size and sampling technique}

Fifteen interviews with dispensers working at community pharmacies in Islamabad, Lahore and Peshawar were conducted. The dispensers (Table 1) were recruited through personal contacts and snowball sampling technique from pharmacies in Islamabad, Peshawar and Lahore. The identified participants were contacted in person or on phone to fix interview appointments. Written consent was obtained from the participants prior to the interview.

\section{Study tool}

Semi-structured interviews were used to collect data. An interview guide was developed for the respondents. The interview method was chosen over the other methods because a number of aspects to be addressed were already identified from the literature and this ensured that the key issues regarding dispensing practices were covered with all the respondents. The pretesting of the guide was conducted with four dispensers.

The interviews were conducted from April 2008 to June 2008 at the practice setting of the respondents. The interviews mainly focused on the perceptions of dispensers on current dispensing practices at community pharmacies, their quality, ideal and current role of dispensers, influences of regulations and stakeholders, and suggestions for improving the current scenario. Probing questions were used where necessary and participants were given 
freedom to express their views at the end of the interview session. Each interview lasted approximately for $20-30 \mathrm{~min}$ and was conducted at respondents' offices during working hours for their convenience. All the interviews were conducted in the local language. Permission for recording was obtained and if not permitted, field notes were taken.

Table 1: Demographic characteristics of dispensers working in community pharmacies

\begin{tabular}{|c|c|c|c|c|}
\hline Code & Gender & Province & City & $\begin{array}{l}\text { Position/ } \\
\text { Status }\end{array}$ \\
\hline$\overline{\mathrm{DS}} 1$ & Male & $\begin{array}{l}\text { National } \\
\text { Capital }\end{array}$ & Islamabad & $\mathrm{PO}$ \\
\hline DS 2 & Male & Punjab & Lahore & Owner \\
\hline DS 3 & Male & $\begin{array}{l}\text { National } \\
\text { Capital }\end{array}$ & Islamabad & $P Q$ \\
\hline DS 4 & Female & $\begin{array}{l}\text { National } \\
\text { Capital }\end{array}$ & Islamabad & $P Q$ \\
\hline DS 5 & Male & $\begin{array}{l}\text { National } \\
\text { Capital }\end{array}$ & Islamabad & Owner \\
\hline DS 6 & Male & Punjab & Lahore & $P Q$ \\
\hline DS 7 & Male & $\begin{array}{l}\text { Khyberpakh- } \\
\text { tonkhaw }\end{array}$ & Peshawar & Owner \\
\hline DS 8 & Male & $\begin{array}{l}\text { Khyberpakhto } \\
\text { nkhaw }\end{array}$ & Peshawar & Owner \\
\hline DS 9 & Female & $\begin{array}{l}\text { National } \\
\text { Capital }\end{array}$ & Islamabad & $P Q$ \\
\hline DS10 & Male & Punjab & Lahore & $\begin{array}{l}\text { Pharmacy } \\
\text { Manager }\end{array}$ \\
\hline DS11 & Male & $\begin{array}{l}\text { Khyberpakhto } \\
\text { nkhaw }\end{array}$ & Peshawar & $P Q$ \\
\hline DS12 & Male & $\begin{array}{l}\text { Khyberpakhto } \\
\text { nkhaw }\end{array}$ & Peshawar & Owner \\
\hline DS13 & Male & Punjab & Lahore & $\mathrm{PO}$ \\
\hline DS14 & Male & $\begin{array}{l}\text { Khyberpakhto } \\
\text { nkhaw }\end{array}$ & Peshawar & $\mathrm{PO}$ \\
\hline DS15 & Male & Punjab & Lahore & Owner \\
\hline
\end{tabular}

DS = Dispenser $; P O=$ Pharmacist/owner $; P Q=$ Pharmacists $/$ qualified person

Interviews were transcribed verbatim, translated into English and transcripts were verified by the researcher for their accuracy by listening to the tapes. The transcripts were then analyzed line by line, read repetitively by the experts and thematically analyzed for its content [13].

\section{RESULTS}

The interviews with dispensers focused on three major components i.e. dispensing practices, regulation and influencing factors, and suggestions for improvements. Thematic content analysis of these components yielded additional major themes and sub-themes.

\section{Themes}

\section{Theme 1: Services provided at community pharmacies}

In the view of most of the dispensers, community pharmacies provide quality medicines and services to the public.

'We are providing services at doorstep due to which regular and economical availability of medicines to the community has improved, we also provide counselling and sell local company medicines; we have broken the monopoly of multinational companies' (D.S. 1)

'We provide services like selling medicines, also provide drug information along with diagnostic services; we also prescribe' (D.S 5)

\section{Theme 2: Quality of service provided by community pharmacies}

Different opinions of dispensers were observed regarding the quality of services provided by the community pharmacies. Most of them think that the quality of services provided is good and fulfills the demand of the profession. Few think that the quality of services is average and is fulfilling the demand of the profession to some extent. While some think that it is not good and not meeting the demands of the profession.

'The quality of services provided by pharmacies is good and fulfils the demand of the profession as there is access to medicines by the patient' (D.S 2)

'Pharmacies in the country are fulfilling professional demands to some extent' (D.S 4)

'Pharmacies in the country are not fulfilling professional demands and quality of services is poor' (D.S 1) 


\section{Theme 3: Expectation from community pharmacies}

Provision of advice and compliance with legal requirements of the pharmacy are the major expectations of the dispensers.

'We expect that pharmacies shall comply with legal requirements like temperature control, check on narcotic and control medicines' (D.S6)

'Pharmacies should be properly maintained and prescription check should be carried out along with counselling' (D.S 10)

'Pharmacies are the place to obtain medicines along with information' (D.S 11)

\section{Theme 4: Responsible for dispensing}

In the view of most of the dispensers, the pharmacist is considered as the responsible person for dispensing but in actual practice it is performed by non-qualified persons.

'Currently, non-qualified persons are responsible for drug selling and this is due to low profit margins as we cannot afford a pharmacist; also there is a shortage of qualified pharmacists but the actual responsible person to sell medicine is the pharmacist' (D.S1)

'Pharmacist is responsible for dispensing of medicines; however, anyone who has done matric (higher secondary education, i.e., ten years of schooling) comes into this profession and this is due to lack of interest of the government' (D.S 4)

\section{Theme 5: Obstacles to appropriate dispensing practices}

Inadequate number of pharmacists and their missing role were seen as the major obstacle to appropriate dispensing practices by most of the dispensers.

'Drug sellers perform the role of doctors; they diagnose, prescribe as well as give away medicines because the doctor's fee is too high and people can't afford it and come directly to the private pharmacy' (D.S 1)

'Drug sellers perform an important an role in the society by providing medicines along with making diagnosis and offering patient education and this is accepted as it has always been practised over a very long time' (D.S 3)

'The role of the pharmacist is to check prescription for drug interactions and if there is any problem, consult with the doctor, and also maintain the environment of the pharmacy according to laid down standards (D.S 5)

'Current role of the pharmacist in pharmacies is negligible; however, if he/she is present, then people trust and rely on their advice (D.S 9)

\section{Theme 6: Laws and factors governing pharmacy practice in Pakistan}

Most of the dispensers are aware of factors such as the Drug Act of 1976, government, chemists and their associations but believe that doctors are the main influence on the practice of pharmacy in Pakistan.

'Investors, owners, Ministry of Health doctors and patients are responsible for influencing the way pharmacies operate. Drug laws are there but they are not adequate without proper implementation, and moreover, the current law has not ensured the presence of qualified personnel in pharmacies' (D.S 4)

'The factors influencing pharmacy practice includes law, prevailing environment and socioeconomic factors. The laws do not match the reality on ground and although copies are pasted but there is lack of the practicing dimension and frame work for implementation. There is lack of qualified persons and most of the pharmacists are employed in the industry. Government should look at the minimum standards for retail outlet, and on-job training should be provided' (D.S 5)

'Proprietors, patients and doctors are the major influences. The laws are not adequate to cover all aspects of pharmacy operations 
which need improvement. Implementation is the major issue which should be tackled by the government' (D.S 10)

\section{Theme 7: Strategies to improve the current dispensing practice}

Most of the dispensers think that the government of Pakistan should assume responsibility of improving the current scenario:

a) Availability of qualified person:

'Bring more pharmacists into community pharmacy practice and give them more incentives; generic medicines should be promoted to reduce prices and this should be done by the Ministry of Health' (D.S 1)

'Consumers should come to the pharmacy and ask for pharmacist and this can only happen if there is consumer awareness' (D.S 9)

'The pharmacies should procure medicines from proper sources and store them according to regulations; qualified persons must be present. I think the pharmacist and government should both take joint responsibility for improving the current situation regarding dispensing practices in the country' (D.S 10)

b) Training of proprietors:

'First of all, the implementation of the law should be so firm that all pharmacies should be run by pharmacists only; theonly other option is to train drug sellers to running pharmacy outlets properly' (D.S3)

If a qualified person is not present, other persons employed in the pharmacy can work but they should be trained to do the job.

c) Relaxation of existing drug laws:

'Relaxation of the requirements of the law can be one of the important steps in improving the current situation; actually government should take this step and make laws easy to understand and implement; current dispensing practices are good' (D.S 15)

\section{DISCUSSION}

Dispensers have an important role in ensuring appropriate dispensing practices. This study provides an insight into the perceptions of dispensers regarding dispensing practices in the country. All the dispensers were of the view that dispensing practices are not up to the mark and their approach is more commercially oriented than professional. A study undertaken in Palestine also found that community pharmacy operations were more business-oriented than health services oriented [14].

Nearly all the respondents perceived that the services rendered by pharmacies were mostly providing medicines and due to the shortage of professionally qualified persons, dispensing function is performed by nonqualified personnel. Absence of qualified persons in pharmacies has also been reported in Vietnam, Sri Lanka and India [1517].

Low demand for counselling by the public was the answer given by most of the interviewees when asked about the reasons for inadequate counselling. The findings were consistent with another study reporting lack of adequate knowledge of patients/customers due to their low demand for the provision of information from dispensers working in community pharmacies [18].

The Drug Act of 1976 and government regulate dispensing practices in community pharmacies. Ambiguity of laws and in their implementation appear to be a major problem for inappropriate dispensing practices in the community pharmacies, and interestingly, all the interviewees agreed on this inadequacy in the Pakistani health care system. Weakness of regulatory authorities, lack of trained and competent inspectors as well as inadequate resources were some of the reasons cited [19-20].

With regard to strategies to improve the current situation, the respondents indicated 
that the situation can be improved by ensuring that the pharmacist plays his/her role well in community pharmacies, removing the ambiguities in law and as well as training existing personnel engaged in dispensing practice. Studies from Hanoi, Vietnam, Laos and Palestine highlighted the need for the enforcement of regulations at community pharmacies. Other evidence also suggests the need for the training of dispensers as well as improvement in dispensing practices in community pharmacies [20].

\section{Limitations of the study}

The study was conducted in the three cities of Pakistan. Although, it is likely that the dispensers in other parts of the country would have similar perceptions regarding dispensing practices, the findings may not be generalizable to other cities in country. Furthermore, interviews were recorded where permission was granted; however, where permission was not given to record the interview, field notes were taken and therefore the possibility of loss of information cannot be ruled out.

\section{CONCLUSION}

These findings suggest that community pharmacies have been able to improve access to medicines by just providing medicines to the masses but rendered limited services in terms of counseling. There is a need for the strict implementation of laws that require the presence of professionally qualified persons in community pharmacies, as well as training of personnel through the collaborative efforts of all stakeholders. The insights gained from this study should be useful to stakeholders in designing programs to improve on current dispensing practices and public awareness regarding the role of community pharmacies.

\section{REFERENCES}

1. Benjamin H, Smith F, Motawi MA. Drugs dispensed with and without a prescription from community pharmacies in a conurbation in
Egypt. East Mediterr Health J. 1996; 2(3): 506514

2. Hafeez A, Kiani AG, Ud-Din S, Muhammad W, Butt K, Shah Z. Prescription and Dispensing Practices in Public Sector Health Facilities in Pakistan: Survey Report. J Pak Med Assoc. 2004; 54: 187-191.

3. Qadwai W, Krishanani MK, Hashmi S, Afridi M, Al ARA. Private Drug Sellers Education in Improving Prescribing Practices.JCPSP. 2006; 16(12): 743-746.

4. Rabbani F, Cheema FH, Talati N, S Siddiqui, S Syed, $S$ Basir. Behind the counter:pharmacies and dispensing patterns of pharmacy attendants in Karachi. J Pak Med Assoc. 2001; 51(4): 149154

5. Basak SC, Prasad GS, Arun KA, Senthil SK. An attempt to develop community pharmacy practice: Results of two surveys and two workshops conducted in tamilnadu. Indian $J$ Pharm Sci. 2005; 67(3):362-367.

6. Goodman C, Mutemi W, Baya K, Willetts A, Marsh V. The cost-effectiveness of improving malaria home management: shopkeeper training in rural Kenya. Health Policy Plann. 2006; 21(4): 275-288.

7. Tumwikirize WA, Ekwaru PJ, Mohammed K, Ogwal OJW, Aupont O. Management of acute respiratory infections in drug shops and private pharmacies in Uganda a study of counter attendants' knowledge and reported behaviour. E Afr Med J. 2004; 81: 33-40.

8. Degnan R, Soumerai SB, Goel PK, Bates J, Makhulo $J$, Dondi NC. The impact of face-to-face educational outreach on diarrhoea treatment in pharmacies. Health Policy Plann. 1996; 11(3): 308-318.

9. Yousef AMM, Amal G, Bakri A, Bustanji Y, Wazaify M. Self-Medication Patterns in Amman, Jordan. Pharm World Sci. 2008; 30: 24-30.

10. Igun UA. Why we seek treatment here: Retail pharmacy and clinical practice in Maiduguri, Nigeria. Soc Sci Med. 1987; 24(8): 689-695.

11. Syhakhang $L$, Freudenthal SO, Thomsan G, Wahilstrom R. Knowledge and perceptions of drug quality among drug sellers and consumers in Lao PDR. Health Policy Plann. 2004; 19(6): 391-401.

12. Butt $Z A$, Gilani $A H$, Nanan $D$, Sheikh AL, White AF. Quality of pharmacies in Pakistan: a crosssectional survey. Int $J$ Qual Health $C$. 2005; 17(4): 307-313.

13. Hassali M, Kong DCM, Stewart K. Generic medicines: perceptions of consumers in Melbourne, Australia. Inter J Pharm Prac. 2005; 13: 257- 264.

14. Jaradat $N$, Sweileh W. A Descriptive Study of Community Pharmacy Practice in Palestine: Analysis and Future Look. An-Najah Univ. J. Res. (N.Sc) 2003; 17(2): 191-199.

15. Mac TL, Le VT, Vu AN, Preux PM, Ratsimbazafy $V$. $A E D s$ availability and professional practices in 
delivery outlets in a city center in southern Vietnam. Epilepsia. 2006; 47(2): 330-334.

16. Rajakaruna $R S$, Weerasinghe $M$, Alifrangis $M$, Amerasinghea $\mathrm{PH}$, Konradsen $\mathrm{F}$. The role of private drug vendors as malaria treatment providers in selected malaria endemic areas of Sri Lanka. J Vect Borne Dis. 2006; 43: 58-65.

17. Basak SC, Mil Fv, Sathyanarayana D. The changing roles of pharmacists in community pharmacies: perception of reality in India. Pharm World Sci. 2009; 31(6): 612-618.

18. Chuc NTK, Tomson G. "Doi moi" and private pharmacies: a case study on dispensing and financial issues in Hanoi, Vietnam. Eur J Clin Pharmacol. 1998; 55(4): 325-332.

19. Stenson B, Syhakhang L, Eriksson B, Tomson G. Real world pharmacy: assessing the quality of private pharmacy practice in the Lao People's Democratic Republic. Soc Sci Med. 2001; 52(3): 393-404.

20. Attewell J, Blenkinsopp A, Black P. Community pharmacists and continuing professional development-a qualitative study of perceptions and current involvement. Pharm J. 2005; 274: 519-524. 